\title{
Letter
}

\section{Shark fishing and tourism}

In their recent article, Cisneros-Montemayor et al. (2013) compared the global economic value of shark ecotourism with shark fisheries, arguing for prioritization of shark conservation over exploitation. Although studies that appraise the economic value of living resources are valuable, we believe that the data presented by Cisneros-Montemayor et al. considerably underestimate and misrepresent the economic value of sharks. In addition, by juxtaposing the fishing industry against the tourism industry this study ignores the fact that both industries are of global economic importance and rely on healthy shark populations.

Although the methods section of Cisneros-Montemayor et al. is deficient in details (e.g. no description of interview structure or sample size, or extent of tourism expenditure except 'partially attributable to watching'), it is apparent that the value of shark fishing has been substantially underestimated. For example, they report the current landed value of global shark fisheries at USD 630 million per year, based on $720,000 \mathrm{t}$ of sharks being reported to FAO. However, FAO landing data are notoriously underreported for sharks (Clarke et al., 2006; Worm et al., 2013). Therefore, at a minimum, the value of 1.7 million $t$ (Clarke et al., 2006) should have been used, which, after multiplying by USD 0.875 per $\mathrm{kg}$ of landed shark (from the above FAO ratio of value by tonnage), would bring the value to USD 1.5 billion. But even this number would still be an underestimate as it only includes sharks entering the fin trade and does not include export values or end-user products-for comparison, the valuation of tourism included everything from direct expenditures (e.g. dives) to associated accommodation, meals and flights (e.g. Clua et al., 2011).

The article also contains significant errors and omissions. For example, the value of shark-watching in Fiji is reported to be USD 223,000 (Table 1, reportedly based on Brunnschweiler, 2010, which does not address economic value) instead of USD 42.2 million (Vianna et al., 2011). Cisneros-Montemayor et al. also excluded available shark catch data (e.g. Swamy, 1999; Gilman et al., 2007).

In addition, the contrast of shark fishing with tourism can be misleading because different shark populations or species are generally targeted by the two sectors, and because landed sharks are not necessarily fished within a country's territorial waters. For example, the Spanish shark catch consists of a variety of shark species, mostly taken outside territorial waters (Hareide et al., 2007), whereas shark tourism focuses primarily on angel sharks in the Canary Islands (Gallagher \& Hammerschlag, 2011). Cisneros-Montemayor et al. also conclude that sharkwatching is more valuable than landings (their Table 1).
However, the opposite conclusion could be made if the comparison included only the locations with available data for both shark fishing and watching sectors (their Table 1), where tourism is reported to generate a total of USD 190 million and fisheries USD 199 million per year (rather than the presented totals of USD 215 and 199 million, respectively). Half of these locations with values from both sectors had landed values that were 1.7 (Mexico) to 454 (UK) times the value of shark-watching expenditures.

The economic comparison that Cisneros-Montemayor et al. make between the global values of shark ecotourism and shark fishing should be treated cautiously. Many shark populations are depleted and if science-based and precautionary management is not implemented on a large scale both the shark tourism and fishing industries are at risk of being lost. Therefore, rather than contrasting the value of different sectors, we argue that it is more valuable to promote both sustainable fishing and tourism while advocating for rigorous scientific understanding and sustainable management of shark populations.

JUERG M. BRUNNSCHWEILER Independent Researcher, Gladbachstrasse 60, CH-8044 Zurich, Switzerland.

E-mail juerg@gluecklich.net

CHRISTINe A. WARD-PAIGE Independent Researcher www.eShark.org, Halifax, Nova Scotia, Canada

\section{References}

Brunnschweiler, J.M. (2010) The Shark Reef Marine Reserve: a marine tourism project in Fiji involving local communities. Journal of Sustainable Tourism, 18, 29-42.

Cisneros-Montemayor, A.M., Barnes-Mauthe, M., Al-Abdulrazzak, D., Navarro-Holm, E. \& Sumaila, U.R. (2013) Global economic value of shark ecotourism: implications for conservation. Oryx, 47, 381-388.

Clarke, S.C., McAllister, M.K., Milner-Gulland, E.J., Kirkwood, G.P., Michielsens, C.G., Agnew, D.J. et al. (2006) Global estimates of shark catches using trade records from commercial markets. Ecology Letters, 9, 1115-1126.

Clua, E., Buray, N., Legendre, P., Mourier, J. \& Planes, S. (2011) Business partner or simple catch? The economic value of the sicklefin lemon shark in French Polynesia. Marine \& Freshwater Research, 62, 764-770.

Gallagher, A.J. \& Hammerschlag, N. (2011) Global shark currency: the distribution, frequency, and economic value of shark ecotourism. Current Issues in Tourism, 14, 797-812.

Gilman, E., Clarke, S., Brothers, N., Alfaro-Shigueto, J., Mandelman, J., Mangel, J. et al. (2007) Shark Depredation and Unwanted Bycatch in Pelagic Longline Fisheries: Industry Practices and Attitudes, and Shark Avoidance Strategies. Western Pacific Regional Fishery Management Council, Honolulu, USA. 
Hareide, N.R., Carlson, J., Clarke, M., Clarke, S., Ellis, J., Fordham, S. et al. (2007) European Shark Fisheries: A Preliminary Investigation into Fisheries, Conversion Factors, Trade Products, Markets and Management Measures. European Elasmobranch Association.

Swamy, K. (1999) Shark Fisheries in Fiji: Their Management and Issues for Future Concerns. FAO Fisheries Technical Paper No. 378. Food and Agriculture Organization of the UN, Rome, Italy.
Vianna, G.M.S., Meeuwig, J.J., Pannell, D., Sykes, H. \& Meekan, M.G. (2011) The Socio-economic Value of the Shark-diving Industry in Fiji. Australian Institute of Marine Science and University of Western Australia, Perth, Australia.

Worm, B., Davis, B., Kettemer, L., Ward-Paige, C.A., Chapman, D., Heithaus, M.R. et al. (2013) Global catches, exploitation rates, and rebuilding options for sharks. Marine Policy, 40, 194-204. 